\title{
Educação e cidadania: uma experiência pedagógica sobre o Estatuto da Criança e do Adolescente em escola de Ensino Fundamental ${ }^{1}$
}

\author{
Melissa Zani Gimenez* \\ Talita Santana Maciel ${ }^{* *}$ \\ Tânia Suely Antonelli Marcelino Brabo***
}

\begin{abstract}
Resumo
O presente relato de experiência tem como objetivo apresentar a organização de uma sequência de atividades pedagógicas relacionadas ao Estatuto da Criança e do Adolescente (segundo a Lei $\mathrm{n}^{\mathrm{o}}$ 11.525/2007), e refletir sobre sua implementação em uma escola pública paulista de Ensino Fundamental. Constatou-se a viabilidade e importância de expandir esse projeto de educação, buscando a efetividade de direitos já garantidos no plano legal, especialmente porque, no contexto brasileiro, uma parte significativa de crianças e adolescentes encontrase em situação de vulnerabilidade.

Palavras-chave: Estatuto da Criança e do Adolescente (ECA); Direito; Formação cidadã; Educação Escolar.

\section{Education and citizenship: a pedagogical experience on the Statute of the Child and Adolescent in Elementary School}

\begin{abstract}
The present experience report aims to present the organization of a sequence of pedagogical activities related to the Statute of the Child and Adolescent (according to the Law 11.525/2007) and to reflect on its implementation in a public school. It was verified the viability and importance of expanding this education project, seeking the effectiveness of rights already guaranteed in the legal plan, especially since, in the brazilian context, a significant part of children and adolescents is in a situation of vulnerability.

Keywords: Statute of the Child and Adolescent; Right; Citizen training; Schooling.
\end{abstract}

\section{Considerações iniciais}

O início da década de 1980 foi marcado por inúmeras iniciativas de âmbito protetivo às crianças e aos adolescentes, trazendo os avanços da esfera normativa internacional para a população infantojuvenil brasileira, momento em que algumas entidades não-governamentais promoveram trabalhos e criticaram o modelo clássico de intervenção adotado pelo Estado ${ }^{2}$. Atribui-se essas iniciativas aos avanços alcançados na Constituição Federal de 1988 (CF/88), em especial, no que diz respeito à garantia de prioridade absoluta às crianças e aos adolescentes. Após a promulgação da Carta Magna, o Estatuto da Criança e do Adolescente (ECA), Lei Complementar n ${ }^{\circ}$ 8.069/90 (BRASIL, 1990), foi amplamente debatido, escrito e promulgado em clima de campanha cívica.

De acordo com Bazílio (2011), os princípios gerais que nortearam a redação do texto da lei estatutária foram os seguintes: a criança e o adolescente como seres humanos em processo de desenvolvimento; a garantia da condição de sujeitos de direitos fundamentais e individuais; direitos

*Endereço Eletrônico: melgimenez@ hotmail.com

**Endereço Eletrônico: talita.s.maciel@ @otmail.com

****Endereço Eletrônico: tamb@terra.com.br assegurados pelo Estado e conjunto da sociedade como absoluta prioridade. O novo texto, ainda, criou mecanismos de participação da sociedade por meio de diferentes conselhos, entre eles, o Conselho Tutelar e os demais conselhos para o estabelecimento de políticas públicas municipais, estaduais e nacionais (PILOTTI; RIZZINI, 1995).

A partir desse contexto, e em virtude da continuidade da luta dos movimentos sociais em prol da infância e da adolescência, a Lei $\mathrm{n}^{\circ}$ 11.525/2007, de 25 de setembro de 2007, entrou em vigor e alterou a Lei de Diretrizes e Bases da Educação Nacional - LDB, Lei $\mathrm{n}^{\circ} 9.334$ (BRASIL, 1996), estabelecendo a inclusão obrigatória, no currículo do Ensino Fundamental, de conteúdos que tratem dos direitos e deveres das crianças e dos adolescentes, concebendo o ECA como diretriz.

Diante do exposto, o presente relato de experiência visa a apresentar a organização de uma sequência de atividades pedagógicas relacionadas ao ECA e refletir sobre sua implementação em uma escola pública de Ensino Fundamental, localizada no interior do estado de São Paulo. 
A Lei $n^{\circ} 11.525 / 2007$ (BRASIL, 2007) foi apresentada enquanto proposta normativa em 5 de agosto de 2005, transformando-se em lei em 25 de setembro de 2007, junto à Mesa Diretora da Câmara dos Deputados, conforme Diário Oficial da União de 26 de setembro de 2007, página 01. A ideia não foi criar uma nova disciplina, mas, sim, trabalhar questões relacionadas à formação ética e cidadã nas disciplinas já existentes, tornando o Estatuto presente e praticado no cotidiano escolar.

Ter uma lei que promova a educação com base no ECA nas instituições escolares representa uma ação de grande valia que vai ao encontro do campo normativo da educação em direitos humanos (EDH). A escola não pode deixar de ser vista em sua face realista, ou seja, como um lugar em que muitas crianças passam parte significativa de seu dia e, sobretudo, não pode deixar de ser vista em sua essência como instituição de cunho social, consistindo, pois, em ambiente propício e adequado para a implantação do presente ordenamento jurídico, bem como para a prevenção do ato infracional.

A educação cidadã nos moldes do ECA construída no Ensino Fundamental, ao oportunizar à criança e ao adolescente serem conhecedores de seus direitos e responsabilidades ético-sociais, além de transpor as declarações retóricas presentes no diploma infanto-juvenil, pode servir para instaurar, plenamente, as conquistas advindas do Estado Democrático de Direito, em decorrência da educação escolar. Ao elevar a escola à condição de espaço de promoção dos direitos da criança e do adolescente, a Lei $\mathrm{n}^{\text {o }} 11.525 / 2007$ atendeu à doutrina da proteção integral, uma vez que a Lei 8.069/90, que regulamentou o artigo $227^{3} \mathrm{da} \mathrm{CF} / 88$, trouxe aos direitos de crianças e adolescentes o status de prioridade absoluta com ampla garantia de proteção.

Assim, a pergunta que norteou este texto foi: por que construir os saberes a partir do Estatuto da Criança e do Adolescente nas salas de aula? Reitera-se, pois, que a importância do ECA reside não apenas na força da lei, mas no fato de que a escola possui um compromisso real com a sua eficácia, para além de sua vigência.

Uma vez que o ECA nas salas de aula representa um mecanismo de formação ética e cidadã, é possível afirmar que a sua efetividade no processo de ensino e aprendizagem configura-se como uma estratégia de trabalho pertencente à educação em direitos humanos, recente área de estudos no campo acadêmico educacional. Os preceitos basilares que constituem a noção de educação em direitos humanos (EDH) estão imbricados com a história de luta e resistência desencadeada por grupos sociais que buscaram - e ainda buscam - a afirmação de uma cultura cidadã dos direitos humanos. Assim, a EDH é fundada com o intuito de atingir ações coletivas em sociedade, em prol da democracia e contra a violência, a injustiça social, o preconceito e a discriminação.

Nesse sentido, o trabalho com o Estatuto da Criança e do Adolescente na escola pode contemplar algumas das dimensões da EDH a partir da reflexão sobre a ideia de direitos, por meio do ordenamento legal, e a partir, também, dos princípios que fundamentam a formação de sujeitos de direitos. Em face de tais considerações, apresentamos a seguir os caminhos percorridos durante uma intervenção pedagógica, em busca da efetividade da Lei $n^{\circ} 11.525 / 2007$.

\section{Sobre os caminhos percorridos}

A experiência foi realizada durante todo o ano letivo de 2016, com 26 crianças, dentre elas 12 meninas e 14 meninos, que integraram uma turma do terceiro ano do Ensino Fundamental de uma escola pública municipal ${ }^{4}$, localizada no interior do estado de São Paulo, Brasil. A escola é considerada periférica e os alunos que a frequentam pertencem, em sua maioria, à classe socioeconômica média baixa.

Partilharam da vivência aqui relatada, duas estudantes de Pós-Graduação (uma regularmente matriculada no curso de Mestrado e outra no curso de Doutorado) e uma docente do Ensino Superior. Cabe ressaltar que a estudante do curso de Doutorado é também servidora pública e foi professora titular da turma na qual aconteceram as atividades. A professora contou com o apoio direto da estudante de Mestrado em Educação e com o apoio da docente do Ensino Superior, visto que todas integram o mesmo Grupo de Pesquisa cadastrado no CNPq sob o nome NUDISE - Núcleo de Gênero e Diversidade Sexual na Educação. A partir de encontros quinzenais propiciados por ocasião do Grupo de Pesquisa, ambas tinham oportunidade, pois, de planejar, discutir e avaliar o andamento da experiência.

O objetivo da experiência didática foi o de promover atividades pedagógicas relacionadas ao ECA, em busca da efetividade da Lei $n^{\circ}$ 11.525/2007, avaliando o processo educacional.

Assim, embora este trabalho seja fruto de 
uma vivência que se caracteriza enquanto relato de experiência, optamos, como procedimento metodológico, por um instrumento próprio da abordagem qualitativa, muito utilizada em pesquisas científicas, isto é, a observação com registro, na perspectiva teórica de Lüdke e André (1986). Além disso, utilizamos questionários com perguntas abertas, os quais foram analisados por meio de categorias descritivas ${ }^{5}$ a fim de verificar qual o retorno das famílias e das crianças acerca da implementação de ações educativas que estão de acordo com a Lei $n^{\circ} 11.525$ (BRASIL, 2007).

Portanto, os dois primeiros meses do ano letivo foram dedicados a observações das características gerais da turma, e observações e registro das características específicas de cada aluno, incluindo histórico familiar, a fim de que fosse possível pensar em atividades adequadas de intervenção. O próximo passo consistiu em analisar o índice temático da edição do ECA distribuída pelo governo do estado de São Paulo ${ }^{6}$ (SÃO PAULO, 2012) e selecionar os temas mais significativos a serem trabalhados com a turma. A Figura 1 ilustra a organização do índice:

FIGURA 1 - Trecho do índice temático

ATENDIMENTO

Fonte: São Paulo (2012)

Tal índice reúne em cada eixo temático todos os artigos do ECA referentes ao tema. Assim, diante das necessidades da turma, a sequência de atividades deu-se a partir dos seguintes temas: a) alcoólatras e toxicômanos; b) atendimento; c) ato infracional; d) comunidade; e) Conselho Tutelar; f) criança; g) crimes contra a criança e o adolescente; h) cultura; i) dever; j) diversões k) educação l) exploração e abuso sexual; m) família; n) guarda; o) lazer; p) profissionalização q) saúde; r) vida. Além disso, utilizou-se a Parte Geral (Livro I) ${ }^{7}$ do ECA como base para as atividades desenvolvidas. Para cada eixo temático foram planejadas e implementadas em média de dez atividades ${ }^{8}$, de forma que as discussões pudessem ocorrer diariamente. Como estratégias didático- pedagógicas, foram escolhidas aulas expositivas dialogadas, dinâmicas em grupo, atividades lúdicas e lições de casa, a fim de que os conteúdos fossem também compartilhados com as famílias.

No geral, as atividades foram programadas a partir dos títulos I, II e III do primeiro livro do ECA, os quais dispõem sobre o direito à vida, à saúde, à liberdade, dignidade, informação, cultura, lazer, esportes, diversões, educação, entre outros direitos básicos de todo ser humano.

A partir da Figura $2^{9}$ e descrição a seguir, buscamos exemplificar as estratégias didáticopedagógicas utilizadas na organização da sequência de atividades, pautadas nos temas citados anteriormente. 
FIGURA 2 - Exemplo de estratégia didático-pedagógica

Trecho adaptado do conto dos Irmãos Grimm
"Era uma vez um homem cuja primeira esposa tinha morrido, e que tinha casado novamente
com uma mulher muito arrogante. Ela tinha duas filhas que se pareciam em tudo com ela.
O homem tinha uma filha de seu primeiro casamento. Era uma moça meiga e bondosa,
muito parecida com a mãe.
A nova esposa mandava a jovem fazer os serviços mais sujos da casa e dormir no sótão,
enquanto as 'irmãs' dormiam em quartos com chão encerado. Quando o serviço da casa estava
terminado, a pobre moça sentava-se junto à lareira, e sua roupa ficava suja de cinzas. Por esse
motivo, as malvadas irmãs zombavam dela".

Fonte: Godoy (2016)

Normalmente, tomando como eixo central o tema selecionado na organização da sequência de atividades, apresentávamos às crianças uma proposta de texto (como no exemplo, explicitado na Figura 2), variando o uso de gêneros textuais, ou uma proposta de brincadeira, dinâmica, jogo, ou, ainda, algum recurso das artes visuais. Em seguida, eram apresentados alguns dos artigos do ECA a fim de possibilitar a reflexão sobre as situações presentes na proposta do dia. O exemplo exposto na Figura 3 refere-se ao texto da Figura 2:

FIGURA 3 - Artigos do Estatuto da Criança e do Adolescente que nortearam uma proposta de atividade

Art. $2^{\circ}$ Considera-se criança, para os efeitos desta Lei, a pessoa até doze anos de idade incompletos, e adolescente aquela entre doze e dezoito anos de idade.

Art. $5^{\circ}$ Nenhuma criança ou adolescente será objeto de qualquer forma de negligência, discriminação, exploração, violência, crueldade e opressão, punido na forma da lei qualquer atentado, por ação ou omissão, aos seus direitos fundamentais.

Art. 18. É dever de todos velar pela dignidade da criança e do adolescente, pondo-os a salvo de qualquer tratamento, desumano, violento, aterrorizante, vexatório ou constrangedor.

Art. 60. É proibido qualquer trabalho a menores de quatorze anos de idade, salvo na condição de aprendiz.

Art. 13. Os casos de suspeita ou confirmação de castigo físico, de tratamento cruel ou degradante e de maus-tratos contra criança ou adolescente serão obrigatoriamente comunicados ao Conselho Tutelar da respectiva localidade, sem prejuízo de outras providências legai. (Redação dada pela Lei $\mathrm{n}^{\circ}$ 13.010, de 2014).

Art. 56. Os dirigentes de estabelecimentos de ensino fundamental comunicarão ao Conselho Tutelar os casos de:

I - maus-tratos envolvendo seus alunos;

II - reiteração de faltas injustificadas e de evasão escolar, esgotados os recursos escolares;

III - elevados níveis de repetência.

Considerações importantes: Quando a criança e o adolescente não conseguem realizar atividades diárias importantes para seu desenvolvimento cultural, ético, moral, como ir à escola, brincar, participar de atividades culturais, pelo trabalho doméstico excessivo que é 168 obrigado a realizar, está sofrendo maustratos pela prática de trabalho infantil doméstico. Esse costume de trabalho infantil e de maus tratos é proibido e deve ser imediatamente denunciado aos dirigentes escolares e ao Conselho Tutelar pela pessoa em desenvolvimento e/ou por um adulto.

Fonte: Brasil (1990) 
Por fim, realizávamos rodas de conversas e atividades pedagógicas escritas (como produções de textos coletivos, por exemplo). Nos momentos de conversa, as crianças eram estimuladas a falar e surgiam expressões de sentimentos, emoções, bem como colocações sobre o cotidiano, pois as crianças, na maioria das vezes, vinculavam os conteúdos trabalhados com algo que já viram, ouviram, ou, até mesmo, vivenciaram em seu dia a dia. Com a Figura 4 a seguir, pretendemos sintetizar as fases do projeto educacional aqui descrito:

FIGURA 4 - Síntese da organização da sequência de atividades relacionadas ao ECA

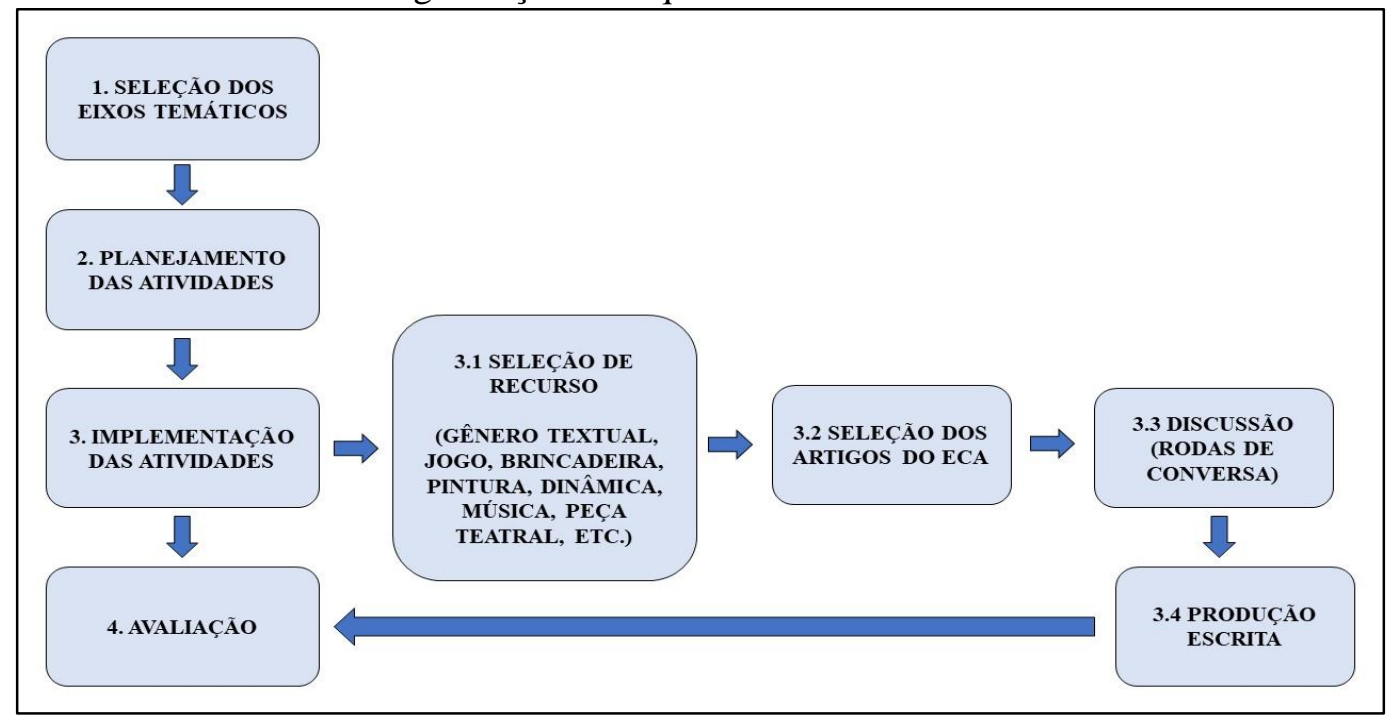

Fonte: Elaboração própria

Como forma de avaliação ${ }^{10}$, as crianças, bem como seus pais ou responsáveis responderam a um pequeno questionário com perguntas abertas e com grande espaço para respostas.

\section{Sobre os questionários}

As crianças responderam a um questionário composto por três questões, cujas respostas foram organizadas em categorias conforme sua frequência, a fim de facilitar a visualização das opiniões por parte do leitor. Dentre as três questões destinadas às crianças, a segunda e a terceira permitiram respostas amplas (Gráfico 1 e Gráfico 2). Já com relação à primeira questão, seu objetivo foi identificar os conhecimentos prévios que as crianças traziam sobre o ECA e compará-los com as respostas das questões seguintes. No entanto, dentre as 26 crianças apenas uma já conhecia o ECA por meio da família (e não por meio da escola), mas não conhecia seu conteúdo, apenas sabia sobre sua existência.

Esse fato nos levou a pensar sobre o (des)cumprimento do campo normativo por parte dos responsáveis pelas instituições escolares. Cabe resgatar aqui, dados de uma pesquisa científicoacadêmica: em abril do ano de 2012, correspondências foram enviadas pela pesquisadora a mais de vinte escolas de Ensino Fundamental solicitando a diretores e Secretários da Educação o retorno da correspondência, a fim de identificar a presença ou ausência de atividades que estivessem de acordo com o cumprimento da Lei $\mathrm{n}^{\circ}$ 11.525/2007. No entanto, até a defesa da dissertação (ano de 2014) apenas dois diretores escolares se manifestaram (GIMENEZ, 2014). Nesse contexto, conforme explana Maior Neto (2013, p. 6) no prefácio do Estatuto da Criança e do Adolescente Anotado e Interpretado:

[...] convém admitir que a lei - ainda que de reconhecida excelência - não tem o condão de, por si só, alterar a realidade social. O que transforma a sociedade é, na verdade, o efetivo exercício dos direitos previstos na lei, a partir de uma atuação firme e decidida daqueles que, de uma forma ou de outra, detém o poder e, por via de consequência, a responsabilidade para criar as condições e os meios indispensáveis ao exercício de tais direitos. 
Com isso, a partir dos dados acima, vale refletir sobre a função social da escola e, constatando-se a grande responsabilidade dessa instituição, pensar sobre os meios pelos quais a efetividade das leis já consagradas pode ser alcançada, tendo em vista a construção de condições mais justas e igualitárias.

As respostas escritas na segunda pergunta foram amplas e foi possível organizá-las em cinco categorias, conforme o gráfico a seguir:

GRÁFICO 1 - Opinião sobre a utilidade do ECA

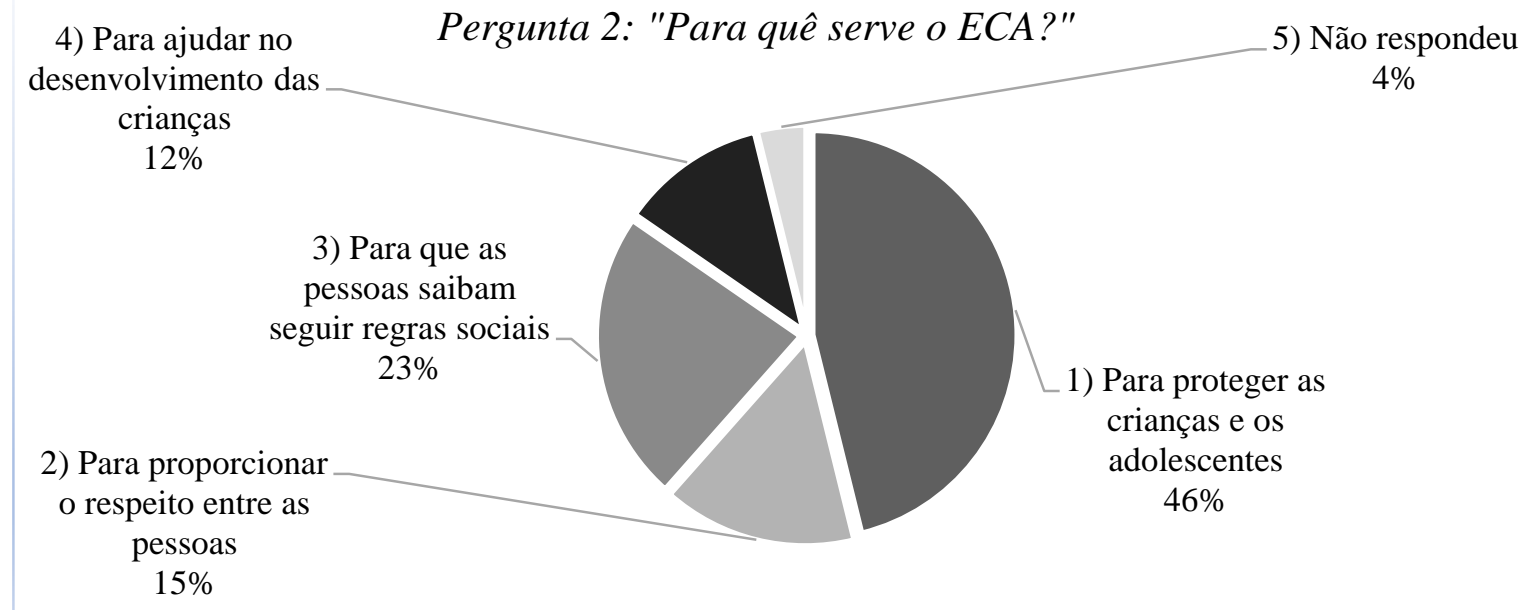

Fonte: Elaboração própria

Observa-se que a maioria das crianças apropriou-se do ECA enquanto um mecanismo de defesa. A análise dos registros realizados a partir da observação evidenciou, nessa mesma perspectiva, aspectos importantes quanto à conscientização e encorajamento para tomada de atitudes por parte das crianças e das famílias.

A seguir apresentamos alguns dos escritos que originaram as categorias acima relacionadas ${ }^{11}$ : "o ECA serve para proteger a criança $e$ o adolescente." (CRIANÇA 10, 2016); "os direitos servem para que as crianças, os adolescentes e os outros respeitem-se." (CRIANÇA 2, 2016); "serve para não ser abusado." (CRIANÇA 15, 2016); "serve para ver respeito." (CRIANÇA 24, 2016); "para aconselhar as pessoas no mundo, para elas saberem o que fazer com as crianças." (CRIANÇA 5, 2016); "para ser reconhecido como cidadão."
(CRIANÇA 9, 2016); "para manter a disciplina nas cidades e para que o povo saiba como fazer." (CRIANÇA 7, 2016); "para ajudar a se desenvolverem e aprenderem." (CRIANÇA 12, 2016); "para ajudar as pessoas que sofrem com o bullying, para ser amigo, ajudar o outro." (CRIANÇA 20, 2016).

As respostas também evidenciaram questões morais e éticas que estiveram envolvidas nas atividades relacionas ao ECA durante o ano letivo. Como se observa, $23 \%$ das respostas referem-se a regras sociais (o ECA como ordenamento jurídico que orienta a sociedade) e $15 \%$ fizeram referência ao respeito, bem-estar coletivo, solidariedade, amizade.

As respostas coletadas na terceira pergunta permitiram a classificação dos dados em três categorias, como ilustra o Gráfico 2: 
GRÁFICO 2 - O que foi possível aprender a partir do ECA

\section{Pergunta 3: "O que você aprendeu com as atividades sobre o ECA?"}

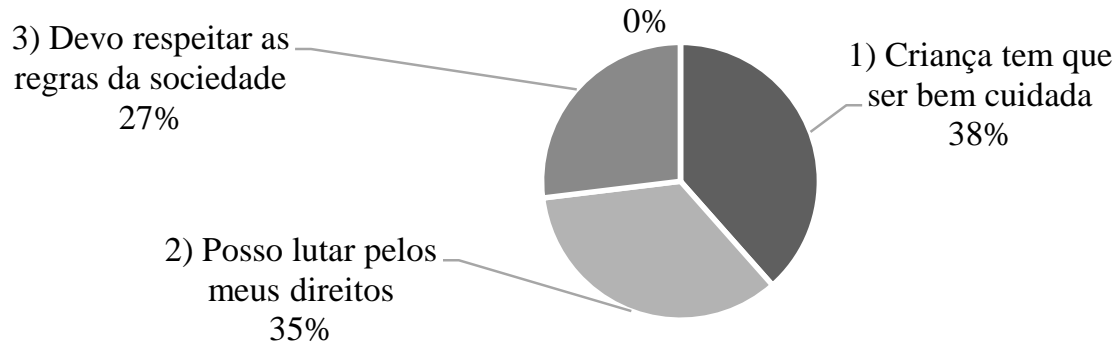

Fonte: Elaboração própria

Escritos como os seguintes apareceram nas respostas: "não devemos agredir ninguém, devemos respeitar as pessoas e o ECA me ensinou a buscar meus direitos." (CRIANÇA 19, 2016); “o ECA é uma lei muito boa para as crianças e os adolescentes, cuida da gente e a gente merece ser cuidado, lutar pelos direitos." (CRIANÇA 4, 2016); "o ECA é legal, uma matéria interessante. Criança, você representa um grande tesouro, o ECA te defende". (CRIANÇA 18, 2016).

As categorias levantadas nessa questão aproximam-se das categorias anteriores, ou seja, a percepção sobre o ECA desenvolvida pelas crianças inclui aspectos morais, éticos, encorajamento e conscientização sobre os meios de proteção legal. É interessante observar que as três categorias possuem frequências muito próximas, ou seja, as opiniões transitaram, quase que de maneira igualitária, entre "regras sociais", "mecanismo de defesa" e "luta por direitos".
As observações e registros contínuos corroboram as respostas escritas no questionário aberto. Embora não seja intenção principal deste texto apresentar resultados precisos, é importante compartilhar que, por meio dos registros, foi possível constatar características iniciais de relacionamento entre as crianças: muitas brigas, palavras de ofensa, muitas crianças com baixa autoestima e muitas outras com dificuldades para se expressarem, tanto no que concerne à fala em público, quanto à expressão de sentimentos. No final do ano letivo, a mudança no relacionamento entre as crianças tornou-se nítida e elas passaram, também, a dirigir-se com maior respeito em relação à professora e demais funcionários da escola.

Outro questionário com duas perguntas abertas foi enviado para que as crianças respondessem juntamente com seus pais ou responsáveis. A primeira delas foi a seguinte (Gráfico 3):

GRÁFICO 3 - Opinião sobre as aulas pautadas no ECA

Pergunta 4: "O que você tem a dizer sobre as aulas planejadas a partir do ECA?"

4) Trouxe conscientização sobre alguns perigos e como agir $39 \%$

Fonte: Elaboração própria.
1) Aulas de extrema relevância social $23 \%$
2) As crianças

passaram a argumentar $19 \%$ autoestima e segurança $19 \%$
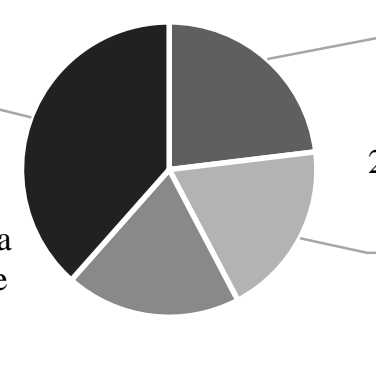

(9) 
Quatro categorias foram criadas com base na frequência das respostas. Os registros também constataram melhorias quanto à autoestima, segurança e argumentação. Desta forma, pode-se afirmar que os benefícios propiciados pelas aulas sobre o ECA estenderam-se para as relações familiares. Alguns dos escritos são os seguintes: "as aulas têm muita relevância social, ela [filha] passou a se dedicar mais na escola e a conhecer seus direitos." (RESPONSÁVEL 1, 2016); "além de promover o que é certo e errado, promoveu crescimento no sentido de observar criticamente as situações." (RESPONSÁVEL 11, 2016); “[...] outro dia conversando em casa, ele [filho] nos ajudou muito falando a respeito do caso de pedofilia, estava na ponta da língua, seguro para falar." (RESPONSÁVEL 8, 2016); "ela [filha] aprendeu que todo mundo é igual, não importa a cor que é, a raça, a religião, etc., temos que respeitar cada um, e isso foi melhorando a autoestima dela." (RESPONSÁVEL 9, 2016).
[...] em um momento de conflito familiar, reconheceu que não estava em um ambiente adequado a ele [filho], citando isso, percebi que o aprendizado gerou amadurecimento [...]. Hoje ele é capaz de reconhecer ameaças, perturbações que podem prejudica-lo e a facilidade de expor uma situação negativa que o amedronte. (RESPONSÁVEL 20, 2016)

Durante as discussões desencadeadas no decorrer do ano letivo constatou-se que as crianças e suas famílias possuíam uma ideia pejorativa em relação ao Conselho Tutelar. Nesse contexto, o Conselho Tutelar Municipal foi convidado a participar da construção dos saberes em sala de aula. Portanto, a última pergunta foi escrita com a intenção de verificar se houve (ou não) mudança de concepção. Apenas duas categorias foram criadas com base nas respostas (Gráfico 4):

GRÁFICO 4 - Opinião sobre a parceria escola-família-Conselho Tutelar

Pergunta 5: "O que você pensa sobre a parceria entre a escola, a família e o Conselho Tutelar?"

Fonte: Elaboração própria

A ideia pejorativa deve-se ao fato de que muitas escolas referenciam erroneamente o Conselho Tutelar para ameaçar as crianças e até mesmo as famílias, com a afirmação principal de que o Conselho pode afastar a criança daqueles (as) que possuem sua tutela ou guarda. Porém, ao trabalhar com o verdadeiro sentido do Conselho Tutelar com as crianças e as famílias ${ }^{12}$, observa-se, por meio dos dados, que as respostas foram para além da mudança de concepção, já que 23\% (vinte e três porcento) dos pais ou responsáveis fizeram sugestões, alegando que deve haver melhor integração entre a escola, as famílias e o Conselho Tutelar, incluindo reuniões e planejamento de ações em prol da infância no município. Estas são opiniões representativas: "certos assuntos ficam mais fáceis de lidar quando são abordados em conjunto. A escola ensina, o Conselho ajuda e a família, como obrigação, ajuda a criança a se desenvolver e ser uma pessoa (adulta) de caráter ético." (RESPONSÁVEL 10, 2016); “[...] deve haver, no entanto, mais conversas e debates para melhor planejamento e adequação conjunta de conteúdos para a idade." (RESPONSÁVEL 22, 2016).

Enquanto resultado da experiência, observou-se que o objetivo foi alcançado, na medida em que os alunos passaram a verbalizar ideias 
relacionadas ao ECA, embora não o conhecessem antes do início das aulas, e demonstraram significativo interesse e participação quanto às temáticas abordadas. A experiência também se revelou importante em virtude de ter concedido voz às crianças, respeitando sempre sua condição de sujeitos de direitos. Lee (2010, p. 44) discute sobre $\mathrm{o}$ ato de "dar voz às crianças" e argumenta que, atualmente:

Silenciar as crianças é generalizadamente reconhecido como injustiça, pois torna difícil para elas se defenderem ou procurarem proteção contra o abuso e a exploração, e estabelece limites desnecessários para sua participação na tomada de decisões que afetam suas vidas.

Diante disso, constatou-se a viabilidade e importância de expandir esse projeto de educação pautado no ECA para outras escolas do município e para municípios vizinhos nos próximos anos ${ }^{13}$.

\section{Considerações finais}

A escola exerce um papel de grande valia nesse cenário de implementação de ordenamentos legais e a abordagem do ECA na educação é um meio determinante para torná-los mais conhecidos e compreendidos pela sociedade. Entretanto, ainda são necessários esforços de todas as esferas governamentais para a implementação de políticas públicas voltadas à efetividade dos direitos e deveres presentes na Lei $\mathrm{n}^{\circ} 11.525 / 2007$, fato que, infelizmente, não tem acontecido até o momento atual, mesmo após dez anos desde que esta legislação entrou em vigor (GIMENEZ, 2014).

É necessário, portanto, transpor a Lei $n^{\circ}$ 11.525/2007 para a realidade escolar da criança e do adolescente, ofertando uma nova postura aos docentes do Ensino Fundamental, demonstrando às famílias e à sociedade que a publicação do ementário legal representa um ganho para todos os cidadãos e cidadãs, de tal modo que a criança tem o direito de usufruir desses direitos. Não bastam novas leis. As crianças e os adolescentes necessitam da execução daquelas já existentes, conforme objetiva a Lei $\mathrm{n}^{\mathrm{o}} 11.525 / 2007$, ainda sem muito sucesso. A educação em direitos nas salas de Ensino Fundamental deve ser um instrumento materializador da garantia de melhores condições de vida para aqueles (as) que se encontram à margem social, em especial aqueles(as) considerados(as) jovens infratores(as).

$\mathrm{O}$ questionário entregue à professora, à estudante e à docente do Ensino Superior acerca das atividades pedagógicas implementadas permitiu constatar que a informação sobre o que é uma lei e, sobretudo, a reflexão sobre a ideia de direitos, mobilizou as crianças e também seus responsáveis, visto que assuntos de suma importância e pouco comentados em âmbito familiar, como a pedofilia, por exemplo, passaram a ser problematizados. O conhecimento sobre o amparo que proporciona o plano legal pode evitar e até mesmo cessar situações de atrocidades contra crianças.

O ECA declara que são também as crianças sujeitos de direitos e contribuiu para uma mudança de paradigma no que diz respeito à concepção de criança e de infância ${ }^{14}$, no entanto, por si só, a transição de um paradigma a outro não é suficiente para que os direitos das crianças sejam protegidos. Conforme menciona a própria lei, é dever da sociedade em geral assegurar a efetividade de direitos básicos. E, a escola, enquanto uma das mais importantes instituições sociais, não deve trabalhar nesta perspectiva apenas porque determina a lei, mas, sobretudo, porque possui uma responsabilidade social.

Por fim, ressalta-se que essa foi uma primeira aproximação quanto à busca pela efetividade da Lei ${ }^{\circ} 11.525$ (BRASIL, 2007), cujos resultados contribuirão para a realização de futuras pesquisas científicas, dada a intenção de se expandir o projeto de educação cidadã pautada no Estatuto da Criança e do Adolescente nas salas de aula.

\section{Notas}

1 A materialização desta experiência nos moldes de um relato deu-se devido às reflexões desencadeadas pelas autoras com a intenção de expandir o presente projeto de educação em direitos descrito para outras escolas do próprio município, e para escolas dos municípios vizinhos, em parceria com estudantes bolsistas do Núcleo de Ensino da Universidade Estadual Paulista "Júlio de Mesquita Filho" (UNESP).

2 Antes da promulgação do ECA, duas outras leis regulavam a ação do Estado, a saber, o Código de Menores de 1927 e o Código de Menores do ano de 1979.

3 Segundo o Artigo 227 da Constituição Federal, é dever da família, da sociedade e do Estado assegurar à criança, ao adolescente e ao jovem, com absoluta prioridade, o direito à vida, à saúde, à alimentação, à educação, ao lazer, à profissionalização, à cultura, à dignidade, ao 
respeito, à liberdade e à convivência familiar e comunitária, além de colocá-los a salvo de toda forma de negligência, discriminação, exploração, violência, crueldade e opressão (BRASIL, 1988).

4 Em virtude de questões éticas - especialmente considerando o comprometimento das autoras com relação ao total anonimato da escola e das pessoas participantes da vivência - o nome do município, tampouco da unidade escolar, não foi revelado. Todas as crianças participantes da vivência aqui relatada possuem devida autorização assinada pelos responsáveis.

$5 \mathrm{O}$ processo aqui nomeado de categorização foi o seguinte: após realizar a leitura de todas as opiniões expressas em cada questão, num primeiro momento separamos as respostas segundo um critério de diferenciação entre elas e, após, unimos aquelas que possuíam aspectos de semelhança, criando, assim, categorias descritivas, cada qual com um nome atribuído segundo as características comuns entre as respostas que a compõem.

6 Convém destacar que o índice temático foi selecionado na organização da intervenção apenas por facilitar a busca dos artigos e parágrafos da Lei $n^{\circ} 8.069 / 1990$. O ECA vem sofrendo alterações ao longo do tempo, por isso a cada atividade preparada, consultamos a redação atualizada do ordenamento legal, disponível no link:

http://www.planalto.gov.br/ccivil_03/leis/L8069.h tm.

7 O Estatuto é constituído de dois livros. O livro I autodenomina-se Parte Geral e contém títulos que versam sobre a criança e o adolescente como sujeitos fundamentais e individuais que devem ser assegurados com absoluta prioridade por toda a sociedade e pelo poder público. O segundo livro (livro II, Parte Especial) contém artigos que abordam as políticas de atendimento, as medidas de proteção, prática do ato infracional, responsabilidades dos pais ou responsáveis e o Conselho Tutelar, entre outras.

8 É inviável neste texto a descrição completa de cada uma das atividades, visto que seria necessária a utilização um grande número de páginas. Portanto, limitamo-nos a descrever a organização da sequência de atividades, ressaltando aspectos que elucidam abordagens didáticas selecionadas.

9 É importante destacar que essa proposta se pautou no eixo temático "criança" e apresentou situação de maus-tratos e trabalho doméstico infantil.
Cinderela, no entanto, é uma personagem jovem que, inclusive, se relaciona com um príncipe na história original. Assim, a fim de aproximar a situação em questão do universo de interesse infantil, tornando a atividade prazerosa, a história foi selecionada enfatizando-se aos alunos e alunas que Cinderela deveria ser imaginada como uma criança de 8 anos. Problematizações como a seguinte guiaram, pois, os diálogos: "vocês acham correto Cinderela realizar os trabalhos mais pesados da casa e dormir no sótão, enquanto suas irmãs dormem em quartos limpos?".

10 A palavra avaliação foi aqui utilizada no sentindo proposto pela Resolução CNE/CEB $n^{\circ}$ 4/2010 (BRASIL, 2010), que define Diretrizes Curriculares Nacionais Gerais para a Educação Básica. Dessa forma, o questionário foi aplicado com a intenção de observar a construção do conhecimento por parte das crianças, melhorar a prática pedagógica na perspectiva de efetividade da Lei $n^{\circ} 11.525 / 2007$ e, embora não fosse objetivo inicial da intervenção, foi aplicado com a intenção de verificar a viabilidade de extensão das ações empreendidas, nos moldes em que foram propostas inicialmente.

11 Os escritos das crianças foram corrigidos ortograficamente em sala de aula para que pudessem ser aproveitados neste texto. Nessa ocasião de correção, aproveitamos para realizar debates com base nas opiniões expressas em cada questão.

12 Exploramos juntamente com as crianças os artigos 131 e 136 que referem-se, respectivamente, à conceituação e atribuições do Conselho Tutelar.

13 No ano atual (2018), a implementação de atividades planejadas na perspectiva aqui tratada está em curso na mesma escola onde realizou-se a experiência no ano de 2016. O projeto de expansão está em fase de correção e será enviado para processo de análise quanto à parceria com a Universidade Estadual Paulista "Júlio de Mesquita Filho".

14 Historicamente as crianças foram vistas como pertencentes a uma natureza infantil, isto é, a partir da adoção de uma concepção abstrata de infância, já que por muito tempo analisou-se a criança distanciando-a de suas condições objetivas de vida, como se estas fossem desvinculadas das relações de produção existentes na realidade (KRAMER, 2003). 


\section{Referências}

GODOY, C. Cinderela. Site Educacional, 2016.

Disponível em: <

http://www.educacional.com.br/projetos/ef1a4/cont osdefadas/cinderela.html >. Acesso em: 15 ago. 2017.

BAZÍLIO, L. C. Avaliando a implantação do Estatuto da Criança e do Adolescente. In: BAZÍLIO, L. C.; KRAMER, S. Infância, educação e direitos humanos. 4. ed. São Paulo: Cortez, 2011, p. 23-34.

BRASIL. Constituição da República Federativa do Brasil de 1988. Brasília, DF: Senado Federal: Centro Gráfico, 1988. Disponível em: <http://www.planalto.gov.br/ccivil_03/_Ato20072010/2007/Lei/L11525.htm>. Acesso em: 11 ago. 2017.

Lei $n^{\circ} 8.069$, de 13 de julho de 1990.

Dispõe sobre o Estatuto da Criança e do Adolescente e dá outras providências. Disponível em:

<http://www.planalto.gov.br/ccivil_03/leis/L8069.ht m>. Acesso em: 11 fev. 2017.

Lei $n^{\circ} 9.334$, de 20 de dezembro de 1996.

Estabelece as diretrizes e bases da educação nacional. Disponível em:

<http://www.planalto.gov.br/ccivil_03/leis/L9394.ht m>. Acesso em: 20 ago. 2017.

Lei $n^{\circ} 11.525$, de 25 de setembro de 2007. Acrescenta § 50 ao art. 32 da Lei no 9.394, de 20 de dezembro de 1996, para incluir conteúdo que trate dos direitos das crianças e dos adolescentes no currículo do ensino fundamental. Disponível em: <http://www.planalto.gov.br/ccivil_03/_Ato20072010/2007/Lei/L11525.htm>. Acesso em: $11 \mathrm{fev}$. 2017.

. Resolução $n^{\circ} 4$, de 13 de julho de 2010. Define Diretrizes Curriculares Nacionais Gerais para a Educação Básica. Ministério da Educação;
Conselho Nacional de Educação; Câmara de Educação Básica, 2010. Disponível em: $<$ http://portal.mec.gov.br/dmdocuments/rceb004_10 .pdf>. Acesso em: 21 ago. 2017.

GIMENEZ, M. Z. Cultura da cidadania no ensino fundamental - apontamentos sobre a (in)efetividade do Estatuto da Criança e do Adolescente: uma construção do saber jurídico. 2014. 179 f. Dissertação (Mestrado em Direito) - Centro Universitário Eurípides de Marília, Fundação de Ensino "Eurípides Soares da Rocha”, 2014.

KRAMER, S. Política do Pré-escolar no Brasil: a arte do disfarce. 7. ed. São Paulo: Cortez, 2003.

LEE, N. Vozes das crianças, tomada de decisão e mudança. In: MÜLLER, F. (Org.). Infância em perspectiva: políticas, pesquisas e instituições. São Paulo: Cortez, 2010. p. 42-64.

LÜDKE, M; ANDRÉ, M. E. D. A. Pesquisa em educação: abordagens qualitativas. São Paulo: EPU, 1986.

MAIOR NETO, O. de S. S. Prefácio. In: DIGIÁCOMO, M. J.; DIGIÁCOMO, I. de A. Estatuto da Criança e do Adolescente Anotado e Interpretado. Ministério Público do Estado do Paraná. Centro de Apoio Operacional das Promotorias da Criança e do Adolescente, 2013. p. 5-8.

PILOTTI, F.; RIZZINI, I. (Org.). A arte de governar crianças: a história das políticas sociais, da legislação e da assistência à infância no Brasil. Inserir edição. Rio de Janeiro: Instituto Interamericano Del Niño, Ed. Universitária Santa Úrsula, Amais Livraria e Ed., 1995.

SÃO PAULO (Estado). Edição revisada e atualizada do Estatuto da Criança e do Adolescente. São Paulo: Governo do estado de São Paulo, Secretaria de Estado da Justiça e da Defesa da Cidadania, Conselho Estadual dos Direitos da Criança e do Adolescente, 2012.

\section{Sobre as autoras}

Melissa Zani Gimenez: Professora. Advogada. Doutoranda na Pontifícia Universidade Católica de São PauloPUC/SP, sob o subsídio do CNPQ. Mestra em Teoria Geral do Direito e do Estado pelo Centro Universitário 
Eurípedes de Marília, por intermédio da CAPES. Participante do Grupo de Pesquisa GEP - Grupo de Estudos, Pesquisas, Integração e Práticas Interativas, e do Grupo de Pesquisa NUDISE - Núcleo de Gênero e Diversidade Sexual na Educação.

Talita Santana Maciel: Graduada em Pedagogia pela Universidade Estadual Paulista "Júlio de Mesquita Filho" (2015). Mestra em Educação pelo Programa de Pós-Graduação da Universidade Estadual Paulista "Júlio de Mesquita Filho" (2018), por intermédio da CAPES. Integrante do Grupo de Pesquisa NUDISE - Núcleo de Gênero e Diversidade Sexual na Educação.

Tânia S. A. M. Brabo: Mestrado em Educação pela Universidade Estadual Paulista "Júlio de Mesquita Filho" (1997). Doutorado em Sociologia pela Universidade de São Paulo (2003). Pós-Doutorado em Educação pela Universidade do Minho-Braga-Portugal (2007). É professora Assistente Doutora efetiva da Universidade Estadual Paulista "Júlio de Mesquita Filho" (UNESP).

Submetido em outubro de 2017.

Aprovado em abril de 2018. 